\title{
Differential expression of minimal residual disease markers in peripheral blood and bone marrow samples from high-risk neuroblastoma patients
}

\author{
NOBUYUKI YAMAMOTO ${ }^{1 *}$, AIKO KOZAKI ${ }^{2 *}$, TRI BUDI HARTOMO ${ }^{3 *}$, TOMOKO YANAI $^{2}$, \\ DAIICHIRO HASEGAWA ${ }^{2}$, KEIICHIRO KAWASAKI ${ }^{2}$, YOSHIYUKI KOSAKA ${ }^{2}$, MASAFUMI MATSUO ${ }^{4}$, \\ SATOSHI HIRASE ${ }^{1}$, TAKESHI MORI ${ }^{1}$, AKIRA HAYAKAWA ${ }^{1}$, KAZUMOTO IIJIMA ${ }^{1}$, \\ HISAHIDE NISHIO ${ }^{1,3}$ and NORIYUKI NISHIMURA ${ }^{1,3}$ \\ ${ }^{1}$ Department of Pediatrics, Kobe University Graduate School of Medicine, Kobe 650-0017; \\ ${ }^{2}$ Department of Hematology and Oncology, Kobe Children's Hospital, Kobe 654-0081; \\ ${ }^{3}$ Department of Epidemiology, Kobe University Graduate School of Medicine, Kobe 650-0017; \\ ${ }^{4}$ Department of Medical Rehabilitation, Kobe Gakuin University, Kobe 651-2180, Japan
}

Received October 3, 2014; Accepted July 16, 2015

DOI: $10.3892 / 01.2015 .3710$

\begin{abstract}
Neuroblastoma is an aggressive solid tumor that leads to tumor relapse in more than half of high-risk patients. Minimal residual disease (MRD) is primarily responsible for tumor relapses and may be detected in peripheral blood (PB) and bone marrow (BM) samples. To evaluate the disease status and treatment response, a number of MRD detection protocols based on either common or distinct markers for PB and BM samples have been reported. However, the correlation between the expression of MRD markers in PB and BM samples remains elusive in the clinical samples. In the present study, the expression of 11 previously validated MRD markers (CHRNA3, CRMP1, DBH, DCX, DDC, GABRB3, GAP43, ISL1, KIF1A, PHOX2B and $\mathrm{TH}$ ) was determined in 23 pairs of $\mathrm{PB}$ and $\mathrm{BM}$ samples collected from seven high-risk neuroblastoma patients at the same time point, and the sample was scored as MRD-positive if one of the MRD markers exceeded the normal range. Although the number of MRD-positive samples was not significantly different between PB and BM samples, the two most sensitive markers for PB samples (CRMP1 and KIF1A) were different from those for BM samples (PHOX2B and DBH). There was no statistically significant correlation between the expression of MRD markers in the PB and BM samples. These results suggest that MRD markers were differentially expressed in PB and BM samples from high-risk neuroblastoma patients.
\end{abstract}

Correspondence to: Dr Noriyuki Nishimura, Department of Pediatrics, Kobe University Graduate School of Medicine, 7-5-1 Kusunoki-cho, Chuo-ku, Kobe 650-0017, Japan

E-mail: nnishi@med.kobe-u.ac.jp

*Contributed equally

Key words: neuroblastoma, minimal residual disease, peripheral blood, bone marrow

\section{Introduction}

Neuroblastoma is the most frequent extracranial solid tumor in children and is characterized by its extreme heterogeneity, ranging from spontaneous regression to malignant progression. More than half of neuroblastoma patients are stratified into a high-risk group and $<40 \%$ of these high-risk patients can expect long-term survival. This is mainly due to the chemoresistant minimal residual disease (MRD) that is primarily responsible for tumor metastasis and relapse (1-3).

Although tumor cell dissemination is traditionally classified as a late event during tumor progression, accumulating evidence suggests that tumor cells disseminate from the primary lesions even before the formation of overt tumors, and become circulating tumor cells (CTCs) in the peripheral blood (PB) and disseminating tumor cells (DTCs) in the bone marrow (BM) (4-6). Following local and systemic treatment, residual tumor cells remain as CTCs in the PB and DTCs in the $\mathrm{BM}$, as well as cancer stem cells in the primary lesions. Due to the extremely restricted availability of primary tumor samples, $\mathrm{PB}$ and BM samples are mainly used for MRD monitoring in the clinics (7-9).

As sensitive detection of MRD is essential for monitoring disease status and evaluating treatment response in high-risk neuroblastoma patients, a number of MRD detection protocols based on reverse transcription-quantitative polymerase chain reaction (RT-qPCR) markers have been reported (10-13). Although the ideal markers should be exclusively expressed in neuroblastoma cells, the currently available markers are selected by their ability to define a cut-off value that distinguishes neuroblastoma cells from normal PB and BM cells.

To overcome this limitation, the current protocols utilize multiple MRD markers for PB and BM samples, which are either common or distinct. Common MRD markers are reported as three-marker [double-cortin (DCX), paired-like homeobox $2 \mathrm{~b}$ (PHOX2B) and tyrosine hydroxylase (TH)] and eight-marker [(cyclin D1, collapsin response mediator protein 1 


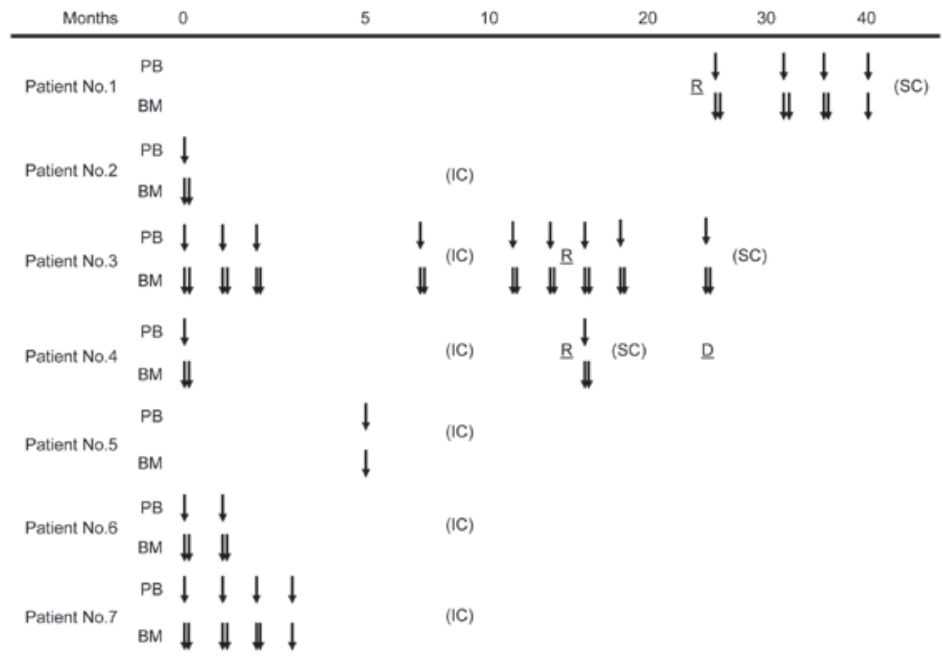

Figure 1. Peripheral blood (PB) and bone marrow (BM) sample characteristics. Downward arrows indicate the time points of minimal residual disease sampling. Month 0 was defined as the time when the primary tumor was diagnosed. IC, induction chemotherapy; SC, salvage chemotherapy; R, tumor relapse.

(CRMP1), dopa decarboxylase (DDC), GABA A receptor $\beta 3$ (GABRB3), ISL LIM homeobox 1 (ISL1), kinesin family member 1A (KIF1A), PHOX2B and transforming acidic coiled-coil-containing protein 2] sets $(10,11)$, while distinct MRD markers are reported as the PB set [PHOX2B, TH, DDC, dopamine $\beta$-hydroxylase (DBH) and cholinergic receptor, nicotinic, $\alpha 3$ (CHRNA3)] and BM set [(PHOX2B, TH, DDC, CHRNA3 and growth-associated protein 43 (GAP43)] (12). However, the rationale for introducing the current protocols into the clinics remains unclear (14-16).

In the present study, we determined the expression of 11 previously validated MRD markers (CHRNA3, CRMP1, DBH, DCX, DDC, GABRB3, GAP43, ISL1, KIF1A, PHOX2B and $\mathrm{TH}$ ) in 23 pairs of $\mathrm{PB}$ and $\mathrm{BM}$ samples collected from seven high-risk neuroblastoma patients treated at Kobe University Hospital and Kobe Children's Hospital, Japan, between November 2011 and April 2014 (13), and analyzed the correlation between PB and BM samples.

\section{Materials and methods}

Patients and samples. All PB and BM samples were obtained from seven high-risk neuroblastoma patients with written informed consent. All patients were treated at Kobe University Hospital and Kobe Children's Hospital between November 2011 and April 2014. The use of human samples for this study was approved by the Ethics Committee at Kobe University Graduate School of Medicine and conducted in accordance with the Guidelines for the Clinical Research of Kobe University Graduate School of Medicine.

RNA extraction and cDNA synthesis. All PB and BM samples were separated using Mono-Poly resolving medium (DS Pharma Biomedical, Osaka, Japan), and nucleated cells were collected according to the manufacturer's instructions. Total RNA was then extracted with a TRIzol Plus RNA purification kit (Life Technologies, Carlsbad, CA, USA) according to the manufacturer's instructions. After evaluating RNA integrity by agarose gel electrophoresis, cDNA was synthesized from 1 or $0.5 \mu \mathrm{g}$ total RNA using a Quantitect reverse transcription kit
(Qiagen, Valencia, CA, USA) and diluted to a total volume of 80 or $40 \mu 1$.

$R T-q P C R$. RT-qPCR was performed using an ABI 7500 Fast real-time PCR system (Applied Biosystems, Foster City, CA, USA) in a total volume of $15 \mu 1$ consisting of $7.5 \mu 12 \mathrm{X}$ FastStart Universal SYBR-Green Master (Roche, Mannheim, Germany), $1.5 \mu \mathrm{l}$ each of $3 \mu \mathrm{M}$ sense and anti-sense primers, and $1 \mu \mathrm{l}$ sample cDNA (corresponding to $12.5 \mathrm{ng}$ total RNA). Each cDNA was amplified with a precycling hold at $95^{\circ} \mathrm{C}$ for $10 \mathrm{~min}$, followed by 40 cycles at $95^{\circ} \mathrm{C}$ for $15 \mathrm{sec}$ and $60^{\circ} \mathrm{C}$ for $60 \mathrm{sec}$, and one cycle at $95^{\circ} \mathrm{C}$ for $15 \mathrm{sec}, 60^{\circ} \mathrm{C}$ for $60 \mathrm{sec}, 95^{\circ} \mathrm{C}$ for $15 \mathrm{sec}$, and $60^{\circ} \mathrm{C}$ for $15 \mathrm{sec}$. Each sample was analyzed in triplicate. The expression of the 11 MRD markers (CHRNA3, CRMP1, DBH, DCX, DDC, GABRB3, GAP43, ISL1, KIF1A, PHOX2B and TH) was calculated based on the relative standard curve method using $\beta 2$-microglobulin as an endogenous reference for normalization, and was scored as positive if its expression exceeded the normal range (13).

Statisticalanalysis.Differences between thenumber ofMRD-positive samples in PB and BM were evaluated by McNemar's Chi-squared test. To assess the correlation between MRD marker expression in $\mathrm{PB}$ and $\mathrm{BM}$ samples, the expression of each marker was ranked according to the number of positive samples in $23 \mathrm{~PB}$ and 23 BM samples. Correlation between the rank in PB and BM samples was assessed by Spearman's rank correlation coefficient. $\mathrm{P}<0.05$ was considered to indicate a statistically significant difference. Statistical analyses were performed with EZR (version 1.24 www.jichi.ac.jp/saitama-sct/SaitamaHP.files/statmedEN.html; Saitama Medical Centre, Jichi Medical University, Saitama, Japan) (17).

\section{Results}

Characteristics of $P B$ and $B M$ samples. The 23 pairs of $\mathrm{PB}$ and BM samples were obtained at the same time point from seven high-risk neuroblastoma patients who were treated at Kobe University Hospital and Kobe Children's Hospital between November 2011 and April 2014 (Fig. 1). Patient characteristics 
Table I. Patient characteristics.

\begin{tabular}{|c|c|c|c|c|c|c|c|}
\hline $\begin{array}{l}\text { Patient } \\
\text { number }\end{array}$ & Age & Gender & $\begin{array}{l}\text { Tumor } \\
\text { origin }\end{array}$ & $\begin{array}{l}\text { INSS } \\
\text { stage }\end{array}$ & $\begin{array}{l}\text { MYCN } \\
\text { status }\end{array}$ & Follow-up & $\begin{array}{l}\text { Present } \\
\text { status }\end{array}$ \\
\hline 1 & $3 y$ & M & Adrenal gland & 4 & Non-amplified & $25-49 \mathrm{~m}$ & $\begin{array}{l}\text { Alive } \\
\text { (Relapsed) }\end{array}$ \\
\hline 2 & $4 y$ & $\mathrm{M}$ & Adrenal gland & 3 & Non-amplified & $0-29 \mathrm{~m}$ & $\begin{array}{l}\text { Alive } \\
\text { (Relapse-free) }\end{array}$ \\
\hline 3 & $2 y$ & M & Adrenal gland & 4 & Amplified & $0-24 \mathrm{~m}$ & $\begin{array}{l}\text { Alive } \\
\text { (Relapsed) }\end{array}$ \\
\hline 4 & $3 y$ & $\mathrm{~F}$ & Adrenal gland & 4 & Amplified & $0-24 \mathrm{~m}$ & $\begin{array}{l}\text { Deceased } \\
\text { (Relapsed) }\end{array}$ \\
\hline 5 & $5 \mathrm{y}$ & M & $\begin{array}{l}\text { Posterior } \\
\text { mediastinum }\end{array}$ & 4 & Non-amplified & $0-17 \mathrm{~m}$ & $\begin{array}{l}\text { Alive } \\
\text { (Relapse-free) }\end{array}$ \\
\hline 6 & $11 \mathrm{~m}$ & M & Adrenal gland & 4 & Amplified & $0-9 \mathrm{~m}$ & $\begin{array}{l}\text { Alive } \\
\text { (Relapse-free) }\end{array}$ \\
\hline 7 & $14 \mathrm{~m}$ & M & Adrenal gland & 4 & Amplified & $0-7 \mathrm{~m}$ & $\begin{array}{l}\text { Alive } \\
\text { (Relapse-free) }\end{array}$ \\
\hline
\end{tabular}

y, years; m, months; M, male; F, female; INSS, International Neuroblastoma Staging System; MYCN, v-myc avian myelocytomatosis viral oncogene neuroblastoma-derived homolog.

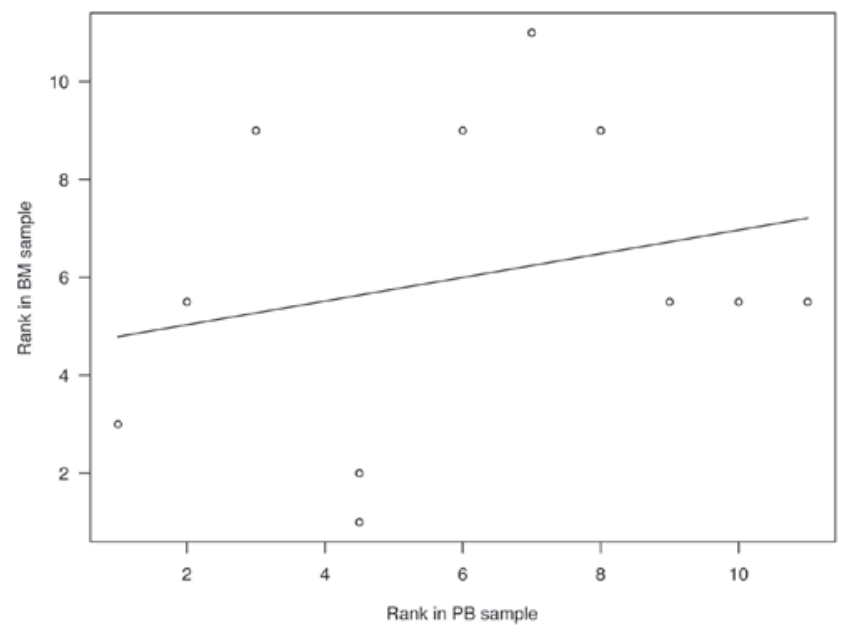

Figure 2. Correlation between minimal residual disease (MRD) marker expression in peripheral blood (PB) and bone marrow (BM) samples. The expression of each MRD marker was ranked according to the number of positive samples in $23 \mathrm{~PB}$ and $23 \mathrm{BM}$ samples. Correlation between the rank in $\mathrm{PB}$ and BM samples was analyzed by Spearman's rank correlation coefficient.

are shown in Table I. All patients were stratified into the high-risk group (18) and treated with induction chemotherapy followed by peripheral blood stem cell transplantation, radiation therapy and surgical therapy according to the Japan Neuroblastoma Study Group protocol. Patients 1, 3 and 4 experienced tumor relapse and underwent salvage chemotherapy. The median follow-up time was 24 months (range, 7-29 months).

CHRNA3, CRMP1, DBH, DCX, DDC, GABRB3, GAP43, ISL1, KIF1A, PHOX2B and TH expression was determined by RT-qPCR, and was scored as positive if its expression exceeded the normal range (13). The number of positive MRD markers in each sample is presented in Table II. A sample was scored as MRD-positive if it had more than one positive marker. There was no statistically significant difference between the number of MRD-positive samples in PB and BM samples (Table III, $\mathrm{P}=1.000$ ).

Correlation between MRD marker expression in $P B$ and $B M$ samples. The number of positive samples of each MRD marker in PB and BM samples is shown in Table IV. CRMP1 and KIF1A were ranked as the two most sensitive markers for PB samples, whereas these were PHOX2B and DBH for BM samples. There was no statistical significance in the correlation between the rank of MRD markers in PB and BM samples (Fig. 2, r=0.250, $\mathrm{P}=0.459$ ).

\section{Discussion}

To improve the outcome of high-risk neuroblastoma patients, sensitive MRD detection is essential for evaluating the disease status and treatment response. Although MRD may be detected in PB as well as BM samples, the correlation of MRD marker expression between the $\mathrm{PB}$ and $\mathrm{BM}$ samples remains elusive. In the present study, we determined the expression of 11 previously validated MRD markers (CHRNA3, CRMP1, DBH, DCX, DDC, GABRB3, GAP43, ISL1, KIF1A, PHOX2B and $\mathrm{TH})$ in 23 pairs of $\mathrm{PB}$ and $\mathrm{BM}$ samples obtained from seven high-risk neuroblastoma patients treated at Kobe University Hospital and Kobe Children's Hospital between November 2011 and April 2014 (13). Although the number of MRD-positive samples was not significantly different between PB and BM samples, there was no significant correlation between the expression of these markers in the samples.

In the present study, we collected the 23 pairs of $\mathrm{PB}$ and BM samples from the same patient at the same time point in order to minimize the variability of MRD marker expression (19). Even under these conditions, the sensitivity of MRD markers in PB samples was clearly different from that in BM 
Table II. Sample characteristics.

\begin{tabular}{|c|c|c|}
\hline \multirow[b]{2}{*}{ Sample pair number } & \multicolumn{2}{|c|}{ Number of positive markers } \\
\hline & PB sample & BM sample \\
\hline 1 & 1 & 3 \\
\hline 2 & 2 & 10 \\
\hline 3 & 0 & 9 \\
\hline 4 & 0 & 0 \\
\hline 5 & 1 & 11 \\
\hline 6 & 1 & 1 \\
\hline 7 & 1 & 0 \\
\hline 8 & 0 & 0 \\
\hline 9 & 1 & 0 \\
\hline 10 & 0 & 1 \\
\hline 11 & 1 & 0 \\
\hline 12 & 2 & 11 \\
\hline 13 & 6 & 11 \\
\hline 14 & 2 & 11 \\
\hline 15 & 1 & 1 \\
\hline 16 & 10 & 11 \\
\hline 17 & 0 & 1 \\
\hline 18 & 0 & 1 \\
\hline 19 & 2 & 1 \\
\hline 20 & 0 & 10 \\
\hline 21 & 1 & 7 \\
\hline 22 & 1 & 0 \\
\hline 23 & 0 & 0 \\
\hline
\end{tabular}

PB, peripheral blood; BM, bone marrow.

Table III. MRD monitoring in PB and BM samples.

\begin{tabular}{lcc}
\hline & \multicolumn{2}{c}{ BM sample } \\
\cline { 2 - 3 } PB sample & MRD (+) & MRD (-) \\
\hline MRD (+) & 11 & 4 \\
MRD (-) & 5 & 3 \\
\hline
\end{tabular}

MRD, minimal residual disease; $\mathrm{PB}$, peripheral blood; $\mathrm{BM}$, bone marrow.

samples (Table IV). KIF1A and DCX were the only positive markers in $\mathrm{PB}$ but not BM samples, whereas $\mathrm{PHOX} 2 \mathrm{~B}$ and $\mathrm{DBH}$ were positive in $\mathrm{BM}$ but not $\mathrm{PB}$ samples. Although $\mathrm{DBH}$ was previously listed as an MRD marker for PB samples (12), the present study identified it as being one of the most sensitive markers in BM samples. As suggested for anti-GD2 antibody and metaiodobenzylguanidine (MIBG) therapies (11), the various treatment protocols might affect these inconsistencies.

Although the quantity of MRD in PB and/or BM samples predicts tumor relapse and patient outcome, conflicting results have been reported with regard to the prognostic value of MRD

Table IV. MRD marker expression in PB and BM samples.

\begin{tabular}{lll}
\hline MRD marker & PB sample
\end{tabular}

\section{CHRNA3}

(+) 119

\section{CRMP1}

$(-)$

DBH

(+)

(-)

DCX

\section{(+)}

(-)

DDC

(+)

(-)

GABRB3

(+)

GAP43

(+)

ISL1

(+)

KIF1A

PHOX2B

TH

$$
\text { (+) }
$$

\section{4}

19

22

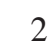

21
8

15

9

MRD, minimal residual disease; $\mathrm{PB}$, peripheral blood; $\mathrm{BM}$, bone marrow; CHRNA3, cholinergic receptor, nicotinic, $\alpha 3$; CRMP1, collapsin response mediator protein 1 ; DBH, dopamine $\beta$-hydroxylase; DCX, double-cortin; DDC, dopa decarboxylase; GABRB3, GABA A receptor $\beta 3$; GAP43, growth-associated protein 43; ISL1, ISL LIM homeobox 1; KIF1A, kinesin family member 1A; PHOX2B, paired-like homeobox $2 \mathrm{~b}$; $\mathrm{TH}$, tyrosine hydroxylase.

monitoring using various MRD markers (14-16). Given that CTCs in the PB and DTCs in the BM define the main faces of MRD in the clinics, these inconsistencies may imply genetic and phenotypic heterogeneity of CTCs and DTCs (20-22). Although CTCs have not been convincingly isolated from neuroblastoma patients, as demonstrated in breast and lung cancers $(23,24)$, the present results reveal the need for careful selection of MRD markers for PB and BM samples. 
In summary, the expression of 11 previously validated MRD markers in PB and BM samples from high-risk neuroblastoma patients was not significantly correlated. Distinct markers for PB and BM samples may be required to achieve sensitive MRD detection in neuroblastoma patients.

\section{Acknowledgements}

This study was supported in part by Grants-in-Aid for Scientific Research from the Ministry of Education, Culture, Sports, Science and Technology of Japan, and grants from the Children's Cancer Association of Japan and Hyogo Science and Technology Association.

\section{References}

1. Brodeur GM: Neuroblastoma: Biological insights into a clinical enigma. Nat Rev Cancer 3: 203-216, 2003.

2. Maris JM, Hogarty MD, Bagatell R and Cohn SL: Neuroblastoma. Lancet 369: 2106-2120, 2007.

3. Maris JM: Recent advances in neuroblastoma. N Engl J Med 362: 2202-2211, 2010

4. Hüsemann Y, Geigl JB, Schubert F, Musiani P, Meyer M, Burghart E, Forni G, Eils R, Fehm T, Riethmüller G and Klein CA: Systemic spread is an early step in breast cancer. Cancer Cell 13: 58-68, 2008.

5. Rhim AD, Mirek ET, Aiello NM, et al: EMT and dissemination precede pancreatic tumor formation. Cell 148: 349-361, 2012.

6. Kang Y and Pantel K: Tumor cell dissemination: Emerging biological insights from animal models and cancer patients. Cancer Cell 23: 573-581, 2013.

7. Müller V, Alix-Panabières C and Pantel K: Insights into minimal residual disease in cancer patients: Implications for anti-cancer therapies. Eur J Cancer 46: 1189-1197, 2010.

8. Lin H, Balic M, Zheng S, Datar R and Cote RJ: Disseminated and circulating tumor cells: Role in effective cancer management. Crit Rev Oncol Hematol 77: 1-11, 2011.

9. Mordant P, Loriot Y, Lahon B, Castier Y, Lesèche G, Soria JC Massard C and Deutsch E: Minimal residual disease in solid neoplasia: New frontier or red-herring? Cancer Treat Rev 38: 101-110, 2012.

10. Viprey VF, Lastowska MA, Corrias MV, Swerts K, Jackson MS and Burchill SA: Minimal disease monitoring by QRT-PCR: guidelines for identification and systematic validation of molecular markers prior to evaluation in prospective clinical trials. J Pathol 216: 245-252, 2008.

11. Cheung IY, Feng Y, Gerald W and Cheung NK: Exploiting gene expression profiling to identify novel minimal residual disease markers of neuroblastoma. Clin Cancer Res 14: 7020-7027, 2008.
12. Stutterheim J, Gerritsen A, Zappeij-Kannegieter L, Yalcin B, Dee R, van Noesel MM, Berthold F, Versteeg R, Caron HN, van der Schoot CE and Tytgat GA: Detecting minimal residual disease in neuroblastoma: The superiority of a panel of real-time quantitative PCR markers. Clin Chem 55: 1316-1326, 2009.

13. Hartomo TB, Kozaki A, Hasegawa D, Van Huyen Pham T, Yamamoto N, Saitoh A, Ishida T, Kawasaki K, Kosaka Y, Ohashi $\mathrm{H}$, et al: Minimal residual disease monitoring in neuroblastoma patients based on the expression of a set of real-time RT-PCR markers in tumor-initiating cells. Oncol Rep 29: 1629-1636, 2013.

14. Stutterheim J, Zappeij-Kannegieter L, Versteeg R, Caron HN, van der Schoot CE and Tytgat GA: The prognostic value of fast molecular response of marrow disease in patients aged over 1 year with stage 4 neuroblastoma. Eur J Cancer 47: 1193-1202, 2011.

15. Yáñez Y, Grau E, Oltra S, Cañete A, Martínez F, Orellana C, Noguera R, Palanca S and Castel V: Minimal disease detection in peripheral blood and bone marrow from patients with non-metastatic neuroblastoma. J Cancer Res Clin Oncol 137: 1263-1272, 2011.

16. Corrias MV, Haupt R, Carlini B, Cappelli E, Giardino S, Tripodi G, Tonini GP, Garaventa A, Pistoia V and Pistorio A: Multiple target molecular monitoring of bone marrow and peripheral blood samples from patients with localized neuroblastoma and healthy donors. Pediatr Blood Cancer 58: 43-49, 2012.

17. Kanda Y: Investigation of the freely available easy-to-use software 'EZR' for medical statistics. Bone Marrow Transplant 48: 452-458, 2013.

18. Castleberry RP, Pritchard J, Ambros P, Berthold F, Brodeur GM, Castel V, Cohn SL, De Bernardi B, Dicks-Mireaux C, Frappaz D, et al: The international neuroblastoma risk groups (INRG): a preliminary report. Eur J Cancer 33: 2113-2116, 1997.

19. Stutterheim J, Zappeij-Kannegieter L, Ora I, van Sluis PG, Bras J, den Ouden E, Versteeg R, Caron HN, van der Schoot CE and Tytgat GA: Stability of PCR targets for monitoring minimal residual disease in neuroblastoma. J Mol Diagn 14: 168-175, 2012.

20. Vermeulen L, de Sousa e Melo F, Richel DJ and Medema JP: The developing cancer stem-cell model: clinical challenges and opportunities. Lancet Oncol 13: e83-e89, 2012.

21. Plaks V, Koopman CD and Werb Z: Cancer: Circulating tumor cells. Science 341: 1186-1188, 2013.

22. Alix-Panabières $\mathrm{C}$ and Pantel $\mathrm{K}$ : Challenges in circulating tumour cell research. Nat Rev Cancer 14: 623-631, 2014.

23. Baccelli I, Schneeweiss A, Riethdorf S, Stenzinger A, Schillert A, Vogel V, Klein C, Saini M, Bäuerle T, Wallwiener M, et al: Identification of a population of blood circulating tumor cells from breast cancer patients that initiates metastasis in a xenograft assay. Nat Biotechnol 31: 539-544, 2013.

24. Hodgkinson CL, Morrow CJ, Li Y, Metcalf RL, Rothwell DG, Trapani F, Polanski R, Burt DJ, Simpson KL, Morris K, et al: Tumorigenicity and genetic profiling of circulating tumor cells in small-cell lung cancer. Nat Med 20: 897-903, 2014. 